\title{
Social Self - organization and Modernization of Government Governance in the Background of Supply - side Reform
}

\author{
Yu He \\ Sichuan Agricultural University, Chengdu, Sichuan, 611130
}

Keywords: Supply Side Reform; Government; Society; Self-Organization; Governance Modernization

\begin{abstract}
Democratic politics, market economy and public society are the three pillars of the existence of modern civil society, the spontaneous organization of society, self-operation, self-development and social service, is the inevitable trend of the country towards modernization, it is to promote the supply side of the structural reform The meaning of the title should be. This paper analyzes the current situation of the development of social self - organization in our country, finds out the influencing factors through the problem, and tries to explore the path of coexistence of social self - organization and government governance and realize the common participation in social affairs management.
\end{abstract}

\section{Introduction}

The stability and development of the state, the order and change of society, depends largely on the combination of internal elements. In the report of the Nineteenth Party Congress, the party and the government stressed that the party and the government, under the guidance of the rule of law and the idea of governing by law, governed the country's administration. The whole country, under the interaction of social structure and economic structure, gradually transferred some power space, Self-organized energy is gradually released. Under the request of promoting the structural reform of the supply side, the social organization has become an effective way to absorb the self-organization demands of the society, and the scientific and rational planning and guidance is the inevitable choice to make it on the right track.

\section{The status of social self-organization}

Since the reform and opening up, China's self-organization in quantity and quality have a qualitative leap. Social organizations have been living in the vast majority of urban and rural areas in China, involving all areas of social life, and gradually formed a wide range, different levels, wide coverage of the social organization system. These social organizations play an active and broad role in China's economy, politics and society. From the overall point of view, the development of China's social organization has seriously lagged behind the needs of China's economic and social development, in the social life of the role played very limited. At the same time, China's social organization system construction and legislation lag behind the actual development of social organizations. Government management of social organizations still take a single, administrative, political means, the community organizations to strictly control the "double review permit system." In addition, there must be many harsh conditions, such as the competent units, a certain registered capital and the same administrative region without similar organizations. Which makes most of our social organizations can not be registered through the registration, had long carrying "illegal" black pot "illegal" activities. Too high threshold and harsh conditions, to a certain extent, bound the development of civil society organizations. 


\section{The social self-organization development dilemma}

The development of social self-organization has created a relatively independent social power that poses a challenge to government leadership and party governance. To the government and the people caused a self-organization has been a strong threat to the stability of the illusion of the regime, so that the government will be characterized as the meaning of the field of heterogeneity, and ultimately to curb its development means; social credibility encountered doubts. Because of its non-governmental nature, the public does not recognize it. For example: in the Yaan Lushan 4.20 earthquake, such as the One Foundation and other self-organization in the earthquake relief, disaster relief materials, donations, etc., but because of its non-government titles, people do not accept their assistance, instead of waiting for government agencies and the organization's rescue. China's self-organization has not yet established a sound rules and regulations, the handling of specific affairs and no scientific planning and procedures. When the self-organization is faced with public affairs and the interests of the masses, the legitimacy, fairness and appropriateness of the handling behavior will be questioned by the public.

The development of social self-organization lacks the support of civic culture. China has long been affected by the feudal culture, a long history of the community only attached to the subjects of the country, and there is no focus on individual rights and autonomy of citizens, leading to the formation of self-organization on the basis of existence and development. The government is still at the helm of society, the civic consciousness is weak, the rule of law and the spirit of public welfare need to be strengthened, which directly leads to the low degree of self attention of self-organization, self-organization due to low attention, its own momentum is also inadequate. So the lack of civic culture caused by the current difficulties of Chinese civil society organizations, restrictions on the development of civil society.

Social self-organization of the substantive law is missing. Substantive law refers to the law that specifies the specific rights and obligations or the specific circumstances of legal protection, which prescribes the main rights and obligations. From the specific content of the legislation, procedural laws and regulations, less substantive laws. At the same time, the contents of the legislation on the ground upside down, not the first civil rights and obligations of the substantive legal norms and the realization of rights and obligations of the procedural laws and regulations, but the introduction of registration management regulations, the establishment of procedural norms in front of the Basic Law, The implementation of the right of citizens to freedom of association is interrupted, the basic rights of citizens can not be effectively protected.

The level of social self-organization legislation is low. At the legislative level, the lack of self-organization of the basic law. The establishment of self-organization is mainly based on the "Regulations on the Administration of Social Organizations Registration", "Provisional Regulations on the Registration and Administration of Private Non-enterprise Units" and "Regulations on the Administration of Registration of Non-governmental Organizations", and the principles of legal retention of freedom of association can not be established And the constitutional requirements of convergence, supporting the legal system. As a result, self-organization can not protect their legitimate rights and interests according to law, the administrative organs can not effectively regulate the self-organization.

\section{The impact of social self-organization on the Chinese government}

On the one hand, self-organization is a partner in the field of government public services, can use their own advantages to assist the government to achieve policy objectives. The scope of self-organization is very broad, involving science, education, culture, environmental protection and social relief and so on. In recent years, there have been many major natural disasters, in the government-led model, self-organized to play their own advantages into disaster relief, assistance and reconstruction activities, it is because the government and self-organization of this understanding and integration of social forces The world has created a disaster reconstruction, the economic recovery of the disaster area miracle. On the other hand, with the continuous 
improvement of the market economic system, the transfer of social functions of institutions, changes in urban social structure has also brought a lot of market can not solve, the Government has solved the problem. These issues are related to the vital interests of the residents, the urgent need for a new self-organization mechanism and the ability to undertake the social carrier. Self-organization of the continuous development of sound, so that the Government can safely put some functions out, will be more human, material and financial resources into the economic, educational, medical and other people's attention is very high, but very difficult problem.

To achieve the government transition, we must rely on the orderly advancement of the political system reform in order to provide support for the government transformation. The realization of political system reform needs the motive and motive force from the inside of the system, and the promotion of social "third party": the role of social "self-organization" in the process of government transformation: First, the restriction of government public power. Self - organization as a force in society, the formation of the formation of public power constraints, can effectively promote political democratization, to promote the political system reform, to achieve government transformation, to provide a strong political foundation. Second, innovative social management. To make our huge society can be scientific and rational operation, the government needs to achieve social management innovation, digging the potential of self-organization to cope with the changing social environment. Third, to promote the effective combination of governance mechanisms. The purpose of government governance in the period of social transformation should be to use the power to guide, control and regulate the various activities of citizens in order to maximize the public interest, especially in the case of social anomie, the implementation of government regulation is to make the healthy development of society Effective protection. In a number of areas, for self-organization to participate in government governance to establish a common vision and basic principles of development, and promote the modernization of governance systems and governance capabilities.

The government is the helm of the whole country, and is the maker of law, policy and development plan. Social self-organization can not stand on the government's position, but within a certain range can affect the government administration, and for the representatives of the group to obtain benefits and provide services. At present, self-organization has become the "spokesperson" of the interest groups. In order to maximize the interests of the group, it is bound to compete with the government for interests, cut into the weak areas of government power and solidify the already existing interests. In the original social structure, the government almost dominated all the organizations, in the allocation of resources, the distribution of benefits, public utilities have a strong role, and the current large number of new self-organization, freedom and mobility, so that they Do not want to accept political leadership, do not want to have a spell to bind themselves. These factors are directly caused by the Government in the exercise of the functions of the time, have to consider the balance of interests of all parties to appease the parties emotions. Social "self-organization" phenomenon due to the growth of social forces, on the surface with the party's grass-roots organizations forward and backward translocation, offensive and defensive conversion, the actual social power on the party and government authority of the challenge, but also the formation of a social supervision force.

First, it is difficult for the government to play a role within the organization itself. Many societies self-organize in the presence of exclusion of official organizations to allow the exclusion of psychological, refused to guide and manage the government. Second, the mass incidents weaken the government's integration of society. Double transformation of the special period, the social repression of the long-standing contradictions blowout out, the local government to deal with the good, good for the people to get support. On the contrary, the government decision-making if the masses have been deprived, oppressed feeling, then everyone may be transformed into social "self-organization" of the convenor, the rapid formation of the spark can start a prairie fire, so that the situation expanded. Third, the hostile reactionary forces with self-organization to influence the government's shaping of society. China is in the realization of the great rejuvenation of the Chinese nation, the key point is bound to be the interests of the re-allocation, smooth through the country is the people of the rich, peace and prosperity, and vice versa is weak national strength, people's 
livelihood. Some self-organized by the external forces, dressed in "self-organized" coat in the country engaged in provoking trouble, religious issues and the collection of state secrets and other illegal facts, create dissonant factors, disrupt our established development track, and ultimately achieve subversion China's sinister intentions. Therefore, how to regulate the good management of social self-organization has become a very difficult problem of the government, but also have to face the reality.

\section{Social self-organization and government relations path}

To improve the participation of social self-organization in government governance, it is necessary to have a good institutional environment, but also need the government and society to self-organize to solve the existing problems in the governance of the interaction, but also the need for self-organization self-improvement, Scientific management.

At this stage to measure the autonomy of Chinese society, to see is the degree of self-organization development. At the same time, the birth and growth of self-organization is also the government's expectations, the more perfect the development of self-organization will be able to help the government to share social responsibility, reduce the government to manage this huge social pressure. Good governance is actually the return of state power to society, the process of good governance is a process of returning to the people. In the process of government governance, we must change the omnipotent gesture, break the interference of old ideas, update the concept of governance, believe in the power of social self-organization, and guide its orderly and lawful participation in the process of governance.

First, the establishment and improvement of social self-organization laws and regulations system, follow the constitutional first. To improve the level of legislation on self-organization, to enhance the authority and binding of the law, to promote the development of social self-organization as soon as possible into the standardization and legal development of the track to ensure that the social self-organization development structure is reasonable and appropriate scale. According to the rule of law, according to the law of administration, its core is to rule by the state, the state should regulate the constitution oath system, establish and improve the constitutional guarantee system, so that the Constitution can play its due constitutional effect, to fully protect the basic rights of citizens. Second, to maintain the relative independence of social self-organization activities. To realize the effective participation of the society in the process of government governance, it is necessary to divorce the government from its real control and affiliation, reduce the government involvement, make it truly independent and autonomous. Third, the reform of social self-organization management and supervision system. The establishment of a special self-organized government management. The establishment of self-organized independent financial and audit system, its financial, organizational activities and management and review supervision. At the same time, self-organization should take the initiative to the public disclosure of data, information, people have the right to query, doubt and self-organization to reply.

Social self - organization needs to establish a perfect organizational structure and scientific mechanism of operation. First, the social self-organization needs to set up with their own mission to adapt to the organization. Between the agencies to clear division of labor, perform their duties, contain each other, the unity of power and responsibility. Second, the establishment of scientific and rational democratic democratic election procedures, master the appointment and removal of personnel, the establishment of democratization, standardization and scientific decision-making mechanism. Third, improve the articles of association, in the framework of the provisions of the law to carry out activities. To organize the articles of association to regulate the behavior and professional ethics of the staff, to ensure the level of practice within the organization. Fourth, regular training of personnel. To achieve the continuous updating of knowledge, the use of the latest and most advanced scientific knowledge to arm their own minds to improve the quality of the organization; and self-organized work focus should always focus on the community to carry out activities, can not deviate from this work center of gravity, self-organized existence and activities will be banned. 


\section{References}

[1] Yu Keping. The rise of Chinese civil society and governance changes [M]. Beijing: Social Science Literature Publishing House .2002.

[2] the Ministry of Civil Affairs of the People's Republic of China website "civil statistics", http://www.mca.gov.cn/statistics/index.html.

[3] Gao Meng, Chen Bing. Towards social construction of public administration [M]. Zhejiang University Press .2013.

[4] Wang Chen. China's non-governmental organizations development of the three adverse institutional factors analysis [J]. Social Sciences .2005, (10).

[5] Hu Xianzhong. Social "self-organization" phenomenon and the work of the youth of the party [J]. Chinese Youth Research, 2013, (9). 